\section{THE ART OF COMPUTATION FOR THE PURPOSES OF SCIENCE.}

\section{I.}

THE art of computation as distinguished from the science of arithmetic it so generally neglected in our ordinary courses of education, that most men and almost all women feel the greatest difficulty and repugnance in dealing with figures. The causes of and remedies for this deficiency are discussed at some length in a paper "On teaching Arithmetic" (Journal of Education, May 1885), and the following remarks refer specially to the requirements of students of science.

I must apologize for the use in proving my case of sume names of high and well-deserved repute. Instances are given, as far as possible, which have been publicly acknowledged or corrected, with the full admission that this paper is itself a house of glass, and that any stone may impinge even upon Newton, since, as Lord Lytton tells us, "that great master of calculations the most abstruse could not accurately cast up a sum in addition. Nothing brought him to an end of his majestic tether like dot and carry one."

In I867 Mr. Stone pointed out two numerical errors in Leverrier's determination of the solar parallax.

Prof. J. D. Van der Plats writes (Chemical Newes, July 30, I886) :- " The verification to which I have submitted the calculations of M. Stas seems superfluous seeing that it deals with the experiments of a savant who has never had an equal in exactitude. It may perhaps astonish some as much as it did me to find that the original memoirs contain numerous arithmetical mistakes, as well as typographical errors, of which some are considerable."

Mr. J. Y. Buchanan writes (NATURE, vol. xxxv. p. 76):"There is a statement in NATURE for November II that the weight of the column of water between 20 fathoms and 70 fathoms from the surface under the westerly equatorial current is only 88 per cent. of the weight of the same column under the easterly counter equatorial current. I regret that a serious arithmetical error occurs in the calculation on which this statement was founded. There is no such considerable difference of weight in the two columns of water." Suppose at the equator the Guinea current flows from west to east at the rate of 40 knots in twenty-four hours, and that the equatorial current flows at 30 knots in twenty-four hours in the opposite direction. The opposite directions of the two currents cause an additive and subtractive difference in the tangential velocity of the particles of water due to the rotation of the earth, and therefore an apparent difference in the acceleration due to gravity of about $1 / 46000$, or a pressure equal to that of an additional $1 / 13$ of an inch of water on the column of 50 fathoms.

On page 84 of the first edition (the second has been corrected) of Prof. Huxley's admirable "Physiography," we read:- " The weight of air on a square mile is about $590,129,971,200$ lbs., and the carbonic acid which it contains weighs not less than $3,08 \mathrm{r}, 870$, 106 lbs., or about $1,375,834$ tons. The weight of the carbon in this carbonic acid is 371,475 tons.'

This short statement contains excellent examples of many of the common arithmetical slips and errors.

The first number is ten times too great, and not quite accurately calculated from the data $(5280)^{2} \times 144 \times 1473$ $=59, \mathrm{I} 33,43 \mathrm{I}, 808$. Multiplying this by $\frac{0532 \mathrm{I}}{\mathrm{I} 00}$, the proportion by mass of carbonic acid in the air, we obtain $31,464,899$; here, besides a slip, the number is again multiplied by ten. The pounds are reduced to tons correctly, but there is a slip in the reduction to carbon, since

$$
\frac{\mathrm{I}, 375,834 \times 3}{\mathrm{II}}=3,5,327 .
$$

Many more instances might easily be brought forward, but the above will suffice to prove that even the highest attainments in science are too often accompanied by inaccuracy in arithmetic. The causes of this defect have been frequently discussed, but, with the exception of De Morgan and his pupils, little advance in the methods of teaching arithmetic seems to have been made since the days of Recorde and Cocker.

The teachers of arithmetic in our public and higher-grade schools are usually good mathematicians who, in their own school-days, have been hurried through the hated subject to higher work, and have had no subsequent experience in the practical computation required in the laboratory, workshop, or counting house. When compelled to work out a sum for themselves, the theory is supplied by their knowledge of algebra, and the practical work by a table of logarithms. When brought face to face with the fact that their pupils dislike and are very weak in arithmetic, they fall back upon the stock argument that they teach arithmetic as a training for the mind, and not as a useful art. In too many cases it is to be feared that they are not teaching arithmetic at all.

The great majority of the text-books in common use seem to be defective from the point of view of a student of science in at least three points.

More than half the rules and examples are devoted to money, and arithmetic is treated as though it applied only to pounds, shillings, and pence.

Secondly, few give any suggestion as to the use of tables in lightening arithmetical work, and a boy leaves school disgusted with long rows of figures in which he sees no utility, and without any idea to how large an extent the work could be lightened.

Lastly, the various methods of dealing with approximate quantities are omitted, and a painstaking boy calculates vast collections of figures of which only two or three have any meaning.

Thus Prof. Huxley gives the tenth figure, 6 , in the expression for the amount of carbonic acid on a square mile, ignoring the facts that while the percentage of carbonic acid varies in the first figure, its density is not known to the fourth, and the pressure of the air varies in the second.

It is convenient to bear in mind the following simple rules, due, I believe, to De Morgan. If two numbers, $a$ and $b$, each true to the first decimal place, are multiplied together, the result is true to $\frac{a+b}{20}$ only; a second true decimal in each number makes the result ten times more correct, and so on. In dividing $a / b$ where each is true to the first place, the result is true to $\frac{a+b}{b^{2} \times \frac{20}{20}}$ and so on. Any attempt at greater accuracy in calculation than is indicated by these results should be avoided, since it only precludes the use of cheap and handy tables, tires the calculator making him more liable to error in the important figures, and tends to give quite a false idea of the accuracy of the experiments on which the calculations are based; unless, indeed, we take seriously the answer of Dulong when asked why he always gave his results to eight figures, "I don't see why I should erase the last decimals, for, if the first figures are wrong, possibly the last are correct."

The natural tendency of the human mind, even if controlled by mathematical and scientific training, is to exalt the accuracy of one's own experiments. This is well shown by Prof. Ramsay and Dr. Young in discussing the vapour-tension of liquid benzene (Proc. Phys. Soc., January 1887) :-

"A curve was drawn to represent these (experimental) relations, and from it three points were chosen, $0^{\circ} \mathrm{C} .26 .54 \mathrm{~mm}$. $40^{\circ} \mathrm{C}$. $180^{\circ} 2 \mathrm{~mm}$., and $80^{\circ} \mathrm{C} .755 \mathrm{~mm}$. The constants for the formula $\log p=a+b a^{t}$ are $a=4.7245^{2}, \log b(-)=0.5185950$, $\log \alpha=\bar{I}$ "996847 $25 . "$ Nine places of decimals are given with apparent confidence, when (I) only three of the whole number of experiments were made even in duplicate; $(2)$ the last pressure, 755, was obtained not by experiment at all, but by extrapolation from a freehand curve, the highest experiment being $79^{\circ} \cdot 6$ and $743^{\circ} \mathrm{I} \mathrm{mm}$; (3) a difference of $1^{\circ}$ at low temperatures produced no change in pressure which was appreciable by the apparatus used. With the above-mentioned constants the author's calculate for $60^{\circ}$ C. $388^{\circ} 5 \mathrm{I} \mathrm{mm}$. Using their data and a table of four-figure logarithms, I find $a=4 \cdot 7239, b=-3 \cdot 3$, $\log \alpha=\overline{\mathrm{I}}^{\circ} 99684$, which gives for $60^{\circ} \mathrm{C} .390 \mathrm{~mm}$. Regnault gives $390 \cdot \mathrm{I} \mathrm{mm}$

Under suitable conditions the observation of one quantity can be made with great exactness. It is possible that Sir George Airy estimated $x / 100$ of a second in a day, or $1 / 8,640,000$; that a balance can be made to estimate $\mathbf{I} / \mathbf{I}, 000,000$ of the load, though those of Stas were only accurate to $1 / 825,000$; and that Sir J. Whitworth measured the $\mathbf{I} / \mathbf{r}, \infty 00,000$ of an inch. These cases, however, are exceptional, and give quite a wrong idea of the accuracy attainable in ordinary observations and experiments, when several operations, each liable to error, have to 
be performed, and various corrections introduced by calculation from extraneous data.

The more closely we examine work of the highest accuracy the more convinced we become of the truth of the statement of Thomson and Tait (p. 333): "Few measurements of any kind are correct to more than six significant figures." Thus the number of inches in a metre was found by Capt. Kater in $182 \mathrm{I}$ to be $39^{\circ} 37079$, and by General Clarke in $\mathbf{1} 866$ to be 39.37043 ; this fundamental datum therefore is affected by a doubt of nearly I/100,000, which of course affects all results dependent on it. In 1856 Miller found that a cubic foot of water at $62^{\circ} \mathrm{F}$. weighs 62.321 lbs. From Kater's result a cubic foot contains 28.3153 cubic decimetres, and the mean of a large number of experiments, especially those of Lefevre Gineau, and Kupffer, make the cubic decimetre of water at $4^{\circ} \mathrm{C}$. to weigh a kilo $=2.20462125 \mathrm{lbs}$. according to Miller. Hence a cubic foot of water at $4^{\circ} \mathrm{C}$. weighs 62.4255 lbs.; and taking the expansion from Förster (1870), which is nearly identical with that used by Miller, the weight at $16^{\circ} .67 \mathrm{C}$. becomes $62.355 \mathrm{lbs}$. ; or about $\mathbf{r} / 2000$ heavier than Miller's determination. But these are the results obtained by picked men under all conditions to insure the greatest accuracy. Results which agree to two or three in the fourth figure show an exceptionally good chemist, while a physicist must be careful indeed to obtain numbers concordant to the fifth figure.

For practical purposes, then, calculations in science may be divided into two classes. The great majority of experiments in physics, chemistry, biology, geodesy, mensuration, navigation, and crystallography are not to be trusted beyond the fourth or fifth figure. Hence a similar accuracy in calculation is all which is required. Some few experiments in each branch-such as the work of Kater, Regnault, Stas, some observations in astronomy, and a few reductions in sociology-may require six or eight figures to be accurately dealt $w$ ith.

In pure mathematics, of course, numerical results may be pushed to any extent compatible with even the partial sanity of the calculator

The following suggestions are intended to assist such of my readers as are not mathematicians in working sums of each class by the aid of tables.

Mechanical aids, such as slide rules, arithmometers, and the like, are purposely omitted, since they would require a paper to themselves. The objection to the larger and more powerful is that they are expensive and complicated ; that they require a good deal of practice on the part of the operator to give accurate results; and that they are not readily adapted to work shorte sums than they are intended for. On the other hand, a slide rule is an almost indispensable servant when once one has learn the use of it for dealing rapidly with comparatively small numbers; for large numbers it becomes very cumbrous.

The two cardinal points in approximate working are the short methods of multiplying and dividing decimals suggested by Oughtred in $163 \mathrm{r}$, and strengthening the last figure retained when the first omitted is above 4. For greater accuracy it is well to mark all strengthened figures, and to allow for an exces or defect of them; as a further security one figure beyond what is required may be calculated.

Tables of the multiples from I to 9 of numbers which frequently occur are of sreat assistance especially when the calculator is tired. They are easily made by repeated additions or by the use of the convenient "automatic multiplier" of Mr. Sawyer, which is merely a modern adaptation of Napier's bones.

The due use of complements and reciprocals saves a good deal of time in subtraction and division.

Tables for general use and special purposes are very numerous. For our present purpose they fall naturally into three classes. Five kinds of tables should be in the hands of all calculators:-

I. Multiplication tables such as those of Crelle, by the aid of which three figures may be dealt with at once with greater certainty than is usually the case with one. Tables of primes and factors are not much required for scientific purposes.

2. Reciprocals, which reduce division to the short multiplication of decimals, render the addition of fractions easy, and assist chemists in percentage compositions.

3. Squares, cubes, square roots, cube roots. For most purposes in chemistry and physics a small table up to Ioo is sufficient, especially when aided by the following convenient method of approximating to a cube root. If $a^{3}$ be the nearest exact cube to the given number $\mathrm{N}, N=(a \pm b)^{3}=a^{3} \pm 3 a^{2} b+3 a b^{2} \pm b^{3}$, or if $b$ be small, $\pm b=\frac{N-a^{3}}{3 a^{2}}$. Thus to find $\sqrt[3]{28}, a=3, b=\frac{28-27}{27}$ $=037, \therefore \sqrt[3]{28}=3.037$ instead of 3.0366 .

De Morgan's edition of Barlow is very convenient, and suffices for all ordinary purposes.

4. Common logarithms to four and five figures. Four-figure tables are perhaps most convenient on one face of a card. Hoizel's reprint of Lalande, with some changes and many valuable additions, is cheap and most convenient in form; it quite suffices for all common work.

For the reasons already mentioned seven-figure tables are unnecessarily cumbrous and expensive for ordinary work. They should never be put into the hands of beginners, as is now the usual practice. Experience shows that boys learn the method of using and appreciate the value of logarithms far more readily than is generally supposed.

5. Gauss's sum and difference logarithms are valuable in dealing with certain trigonometrical formulæ and with questions of expansion.

In the second class may be placed those general tables which are less commonly required, such as :-

I. Powers of 2 and other numbers. Cohn tells us that some varieties of Bacterium multiply by fission every hour, hence by the end of a day one individual would increase to $2^{24}=$ $16,777,216$. We may therefore cease to wonder at the rapicl spread of some forms of infection.

2. Factorials are required in solving permutations and combinations, and therefore in all questions relating to probabilities. Hatchett recommended that a systematic examination of all possible alloys of all the metals should be undertaken. $\mathrm{He}$ forgot to remind anyone who attempted to follow his advice that if only one proportion of each of thirty common metals were considered, the number of binary alloys would be 435 , of ternary 4060 , and of quaternary 27,405 . If four multiples of the atomic weight of each of the thirty metals be taken, the binary compounds are 5655 , ternary 247,660 , quaternary $1,013,985$.

3. The sums of arithmetical series are so readily obtained that they are rarely tabulated.

4. Geometrical series are required in certain social questions, such as the increase of population and the output of coal. Tables of the sums of these series when the ratio is nearly one are common, and of considerable use in some scientific problems.

5. For some purposes it is convenient to express numbers in a scale different from the common decimal one.

Thus (Clerk Maxwell, "Elementary Electricity," p. I80) a series of resistance coils are best arranged according to the powers of 2 , since the smallest number of separate coils is required, and they are most readily tested. The same is true for a set of weights. Thus to express from $I$ to $100 \mathrm{gm}$. 9 weights are ordinarily provided; 9 weights in the scale of 2 will express up to 5 I $1 \mathrm{gm}$., while 7 weights suffice for $100 \mathrm{gm}$., since IOO in the scale of 2 is expressed by 1100100

6. The curious theory of trees clue to Profs. Cayley and Sylvester (B. A. Report, I 875 ) seems to promise the possibility of computing the number of possible compounds formed by elements of given valency. Thus $x$ atoms of tetravalent carbon will combine with monad hydrogen to form $\mathrm{N}$ compounds.

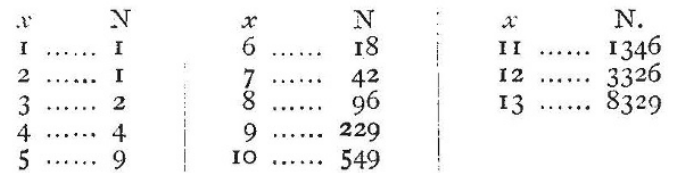

If of the first thirteen paraffin hydrocarbons alone there are $13,95^{2}$ possible forms each with its own series of derivatives, there seems little chance of chemists having nothing to do for some time to come.

7. Natural logarithms are required by some formulæ, and are at times more convenient than common logarithms.

According to Haughton ("Animal Mechanics," p. 282), the study of the action of certain muscles requires the use of natural logarithms.

The ratio of the mean absolute pressure $\mathrm{P}$ to the initial absolute pressure $p$ in a steam-cylinder at the given rate of expansion $r$ is expressed by $\frac{\mathrm{P}}{p}=\frac{I+\text { nat. } \log r}{r}$.

Weldon supposed (B. A. Report, I88I), that some power of 
the atomic weight $(X)$ of each of the first fourteen elements in Mendelejeff's classification is a simple multiple of the same power of the atomic weight of lithium. Or $\mathrm{X}^{x}=m 7^{x}$

$$
l . \mathrm{X}=\mathrm{I} \cdot 9459+\frac{l \cdot m .}{x}
$$

It is easy to see that since $x$ may be any whole number, and $m$ any small whole number, $\mathrm{X}$ may have any value whatever within the limits of errors of experiment ; or the relation is fanciful rather than real.

8. Values of the diefinite integral $\frac{2}{\sqrt{\pi}} \int_{0}^{x} c-x^{2} d x$ represent ing the probability curve, upon which the whole science of the adjustment and comparison of quantitative experiments is based.

Tables of the third class, which offer special facilities to those engaged in any one kind of work, are very numerous.

The physicist has Rankine's "Rules and Tables," Everett's "Units and Physical Constants," Hospitallier's "Formulaire de l'Electricien," and many others.

The chemist has Biedermann's "Kemiker Kalendar," the "Agenda du Chemiste," and various tables for analysis, such as those at the end of Fresenius.

The needs of both physicists and chemists are more or less supplied by Landolt and Bornstein's "Tabellen," the "Annuaire du Bureau des Longitudes," and my own more portable "Numerical Tables and Constants in Elementary Science."

I know of no such numerical compendium dealing with biology, but have often felt the want of one.

To sum up briefly the points which have been so far touched upon. The great majority of numerical problems which really occur in scientific work only require four figures to be accurately dealt with; hence a little ingenuity will generally bring them within the range of small tables. They should be worked out neatly, and as briefly as is consistent with the requisite accuracy ; all useless figures should be rigorously excluded as misleading. Some few problems require the use of more powerful tables. Six-figure tables, such as those in Weale's series, and Collins's Logarithms for practical men, are little used, and inconvenient in practice. Seven-figure tables, such as Callet, Hutton, Babbage, Chambers, Schrön, Bremiker, Bruhns, Sang, so far as numbers go are nearly equally good; they differ chiefly in the trigonometrical ratios, which lie outside our present subject, and also considerably in price.

SxDNEY LUPTON.

(To be continued.)

\section{SOCIETIES AND ACADEMIES. LONDON.}

Zoological Society, Decem'ser 20, 1887.-Prof. W. H. Flower, F.R.S., President, in the chair. - The Secretary read a report on the additions that had been made to the Society's Menagerie during the month of November I 887.-Mr. Sclater read a letter from Dr. H. Burmeister containing a description of a supposed new Humming-bird from Tucuman. Mr. Sclater proposed to call this species, of which the type was in the National Museum of Buenos Ayres, Chatocercus burmeisteri.The Secretary exhibited, on behalf of Major Yerbury, a pair of horns of the Oorial (Ozis cycloceros), which formerly belonged to the Royal Artillery Mess at Fort Attock, and were stated to have been originally obtained in the Chitta Pahar Range, a few miles south of Attock. These horns were apparently of the form lately deseribed by Mr. A. O. Hume as Oz'is blanfordi.An extract was read from a letter received from Mr. H. M. Phipson, of the Bombay Natural History Sxciety, offering some living Snakes for the Society's collection.--Mr. F. E. Beddard read a paper on Hooker's Sea-lion, Otaria (Arctocephalus) hookeri, based upon the specimens of this species recently received by the Society, one of which had lately died. Tne author called attention to the external features, visceral anatomy, and osteology of this Sea-lion, in comparison with the corresponding characters of other species of the group. $\rightarrow \mathrm{Mr}$. G. A. Boulenger read the description of a new genus of Lizards of the family 'l'eiidx, founded on a specimen presented to the British Museum by Mr. H. N. Ridley, who had obtained it in the forest of Iguarasse, Pernambuco. The author proposed to name this Lizard Stenolefis ridleyi.-A communication from the Rev.
H. S. Gorham, entitled a "Revision of the Japanese sprecies of Endomychidce," was read. In this paper three new gezera and thirteen new species were characterized and described. Additional observations were made upon the species previously known to inhabit Japan. The new species were based on specimens obtained by Mr. George Lewis during his last journey to the islands in $1880-8 \mathrm{r},-\mathrm{Mr}$. G. A. Boulenger gave an account of the fishes obtained by Surgeon-Major A. S. G. Jayakar at Muscat, east coast of Arabia, which had been presented by him to the British Museum. The collection contained specimens of 172 species, many of which were unrepresented in the national collection, and fifteen of which were apparently new to science.-Mr. H. Druce read a paper containing descriptions of some new species of Lepidoptera Ieterocera, from Tropical Africa.

\section{EDINBURGH.}

Royal Society, December 19, 1887.--Sir Douglas Maclagan, Vice-President, in the chair.-Mr. John Murray communicated a paper on the height and volume of the dry land, and the depth and volume of the ocean. The mean height of the land above sea-level is 2250 feet. Only 2 per cent. of the ocean is included inside a depth of 500 fathoms. Seventy-seven per cent. lies between depths of 500 and 300 fathoms. The mean depth of the ocean is 12,480 feet. If all the land were utilized to fill up hollows on the earth's surface, the sea would cover it to a uniform depth of 2 miles. - Sir W. Turner read a paper on the pineal gland in the walrus. The gland is excessively developed backwards, being visible from above without any dissection of the brain. The author contrasted it with the same gland in the lizard which is prolonged forwards and ends in the pineal eye. The cerebral lobes in the lizard are small, while those of all mammals are large. He suggested that the development of the lobes may have carried the gland backwards, and caused atrophy of the prolongation ending in the pineal eye. The atrophy, on the other hand, might have been caused by ossification extending over the aperture where the eye. is situated.-Dr. Byron Bramwell described a method which he and Dr. Milne Murray had used successfully to record the exact time-relations of cardiac sounds and murmurs.-Prof. Crum Brown submitted a paper by Prof. Letts on the benzyl phosphines. -Dr. H. R. Mill read a criticism by Dr. Guppy on the theory of subsidence as explaining the origin of coral reefs. Prof. Tait discussed the compressibility of water and of different solutions of common salt. Perkins proved sixty years ago that water becomes less compressible as the pressure is raised. At high pressures then it may be roughly assimilated to an extremely compressed gas. If the gas be regarded as consisting of hard spheres, the curve representing the relation between pressure and volume is approximately hyperbolic. The first asymptote of the hyperbola indicates what must be added to the external pressure to give the whole pressure to which the liquid is subject. The second indicates the ultimate volume to which it could be reduced by an infinite pressure. Applying this to the experimental results given to the Society in July last, the author showed that the pressure in water under ordinary circum itances is somewhere about thirty-two tons' weight per square inch; and the ultimate loss of volume under infinite pressure is about 25 per cent.

PARIS.

Academy of Sciences, December 26, I887.-M. Janssen, President, in the chair.-Annual address, by $M$. Janssen. After brief reference to the losses sustained by the Academy during the year by the deaths of the illustrious savants M.M Paul Bert, Gusselin, Boussingault, and Vulpian, the President passed on to speak of recent scientific progress in France. Special mention was made of the magnificent Observatory just completed at Nice, for which the munificent founder, $M$ Bischoffsheim, receives the Arago Medal, now for the first time awarded. Allusion was also made to the isolation of fluorine effected by M. Moissan, and to the development of stellat photography, declared to be an "invention d'origine toute française." Nevertheless reference is made to the preliminary work of the English and American labourers in this field, Rutherfurd, Warren de la Rue, Bond, and Gould.-Tae Presidential allocution was followed by the announcement $n$ ? the prizes for the year $\mathrm{i} 887$, by the Secretary, M. J. Bertrand, who also read a paper on the life and work of the distinguished engineer, Stanislas Charles H. Laturent Dupuy de Lome. 